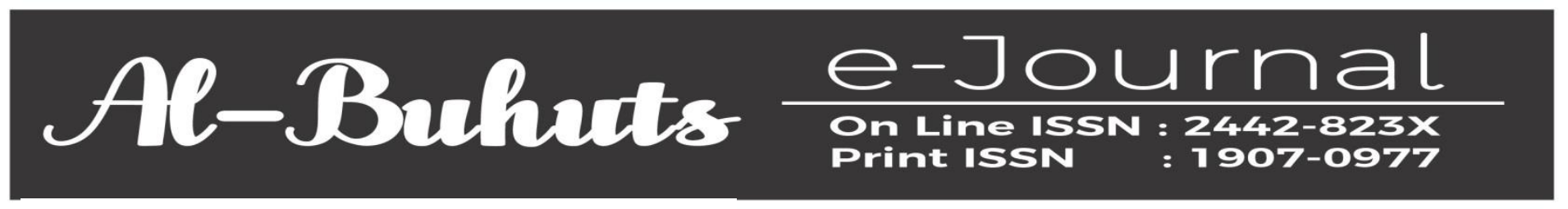

Volume 15 Nomor 2, Desember 2019

\title{
Penerapan E-System Perpajakan dan Tingkat Pemahaman Terhadap Kepuasan Wajib Pajak Pribadi di Kota Makassar
}

\author{
Dahniyar Daud \\ STIEM Bongaya Makassar \\ niardaudismail@gmail.com \\ Musdalifah \\ STIEM Bongaya Makassar \\ ifhasweet87@yahoo.com
}

\begin{abstract}
The purpose of this study was to determine the application of e-taxation systems and the level of understanding of taxation on the level of satisfaction of personal taxpayers in Makassar. This study uses primary data obtained from questionnaires distributed to all taxpayers in Makassar. The population is the taxpayer of individuals registered at the Tax Service Office in the city of Makassar totaling 205,681 taxpayers, while the sample taken amounted to 100 respondents. The data analysis method uses multiple linear regression techniques. The results of this study indicate where the proposed hypothesis is accepted because it shows the results of a positive and significant hypothesis test. This means that the effect of applying the etaxation system and the level of understanding has a significant positive effect on the level of taxpayer satisfaction.
\end{abstract}

Keywords: Application of Taxation E-system, Level of Understanding and Satisfaction Level of Taxpayers

\section{A. PENDAHULUAN}

Dengan adanya peningkatan target terhadap penerimaan pajak ini mendorong Direktorat Jenderal Pajak (DJP) sebagai lembaga yang ditunjuk oleh pemerintah untuk menghimpun penerimaan pajak dengan berbagai upaya diantaranya melakukan reformasi perpajakan berupa penyempurnaan terhadap kebijakan perpajakan dan system administrasi perpajakan (modernisasi sistem administrasi perpajakan) sehingga potensi penerimaan pajak yang tersdia dapat dipungut secara optimal dan menjunjung asas keadilan sosial serta memberikan pelayanan prima kepada wajib pajak. 
Volume 15 Nomor 2, Desember 2019

Halaman 84-92
Penerapan E-System Perpajakan dan Tingkat Pemahaman Terhadap Kepuasan Wajib Pajak Pribadi di Kota Makassar

Modernisasi administrasi perpajakan meliputi kebijakan reformasi administrasi dan reformaasi pengawasan. Reformasi kebijakan terdiri dari amandemen undang-undang antara lain UU No. 36 tahun 2008 mengenai Pajak Penghasilan, UU No. 16 tahun 2009 mengenai Ketentuan Umum dan Tata Cara Perpajakan (KUP), UU No. 42 tahun 2009 mengenai PPN dan PPNBM. Reformasi administrasi merupakan reformasi yang dilakukan berkaitan dengan organisasi, teknologi informasi dan SDM, sedangkan reformasi pengawasan terkait dengan adanya kode etik pegawai seirama dengan pelaksanaan good governance dan equal treatmment dapat berjalan dengan baik .dengan demikian, tujuan dari modernisasi administrasi perpajakan diharapkan tercapainya tingkat kepuasan yang tinggi, kepatuhan yang tinggi, tingkat kepercayaan terhadap administrasi yang tinggi, dan tingkat produkifitas pegawai pajak yang tinggi sehingga penerimaan pajak akan meningkat.

Penulis mencoba mengambil data dari salah satu Kantor Pelayanan Pajak (KPP) diMakassar yakni KPP Makassar Selatan Dalam kurun tahun 2015 sampai dengan 2017, Berikut ini adalah data wajib pajak orang pribadi yang tidak sebanding dengan pengguna efilling pada KPP Pratama Makassar Selatan :

Tabel . Data jumlah wajib pajak dengan banding pengguna e-filling

\begin{tabular}{|c|c|c|c|}
\hline $\begin{array}{c}\text { Wajib } \\
\text { Pajak }\end{array}$ & Tahun & WP Terdaftar & $\begin{array}{c}\text { Jumlah pengguna } \\
\text { E-filling }\end{array}$ \\
\hline $\begin{array}{c}\text { Orang } \\
\text { Pribadi }\end{array}$ & 2015 & 134.274 & 21.226 \\
\cline { 2 - 4 } & 2016 & 145.026 & 54.920 \\
& 2017 & 154.037 & 68.894 \\
\hline
\end{tabular}

Sumber : Pengolah Data dan Informasi KPP Pratama Makassar Selatan

Berdasarkan tabel diatas, jumlah wajib pajak yang terdaftar tidak berbanding lurus dengan wajib pajak pengguna e-sistem seperti e-filling. Hal ini dikarenakan masih kurangnya sosialisasi mengenai e-sistem perpajakan yang terkait dengan fasilitas eregistrasion, e-spt, e-filling menyebabkan kurangnya kesadaran masyarakat untuk berpartisipasi dalam usaha meningkatkan kewajiban perpajakan. Sosialisasi merupakan suatu cara yang dapat di tempuh oleh Direktorat Jenderal Pajak untuk memberi wawasan 
Volume 15 Nomor 2, Desember 2019

Halaman 84-92
Penerapan E-system Perpajakan dan Tingkat Pemahaman Terhadap Kepuasan Wajib Pajak Pribadi di Kota Makassar

kepada wajib pajak agar paham dan mengerti tentang e-sistem yang di keluarkan oleh DJP, karena semakin paham wajib pajak semakin tinggi tingkat kepuasan wajib pajak.

Penelitian ini akan membahas mengenai penerapan pelayanan berbasis e-sistem perpajakan mulai dari pendaftaran dengan e-registrasion, e-spt hingga pelaporan dengan menggunakan e-filling dan hubungannya terhadap tingkat kepuasan wajib pajak dengan tujuan untuk mengetahui sejauh mana penerapan e-sistem perpajakan di terapkan di KPP dikota Makassar.

Berdasarkan uraian diatas, maka peneliti merumuskan masalah penelitian sebagai berikut :

1. Apakah penerapan e-system perpajakan berpengaruh terhadap tingkat kepuasan wajib pajak pada Kantor Pelayanan Pajak dikota Makassar ?

2. Apakah tingkat pemahaman berpengaruh terhadap tingkat kepuasan wajib pajak pada Kantor Pelayanan Pajak dikota Makassar ?

Berdasarkan uraian rumusan masalah di atas, tujuan penelitian ini sebagai berikut :

1. Untuk mengetahui apakah penerapan e-system berpengaruh terhadap kepuasan wajib pajak pada Kantor Pelayanan Pajak dikota Makassar .

2. Untuk mengetahui apakah tingkat pemahaman berpengaruh terhadap kepuasan wajib pajak pada Kantor Pelayanan Pajak dikota Makassar ..

\section{B. METODE}

a. Jenis dan Metode Penelitian

Penelitian ini menggunakan jenis data data kualitatif yang akan di transformaikan menjadi data kuantitatif. Data kuantitatif adalah data yang berbentuk angka berupa skor masingmasing indikator yang diperoleh dari pengisian kuesioner yang dibagikan. Data kualitatif adalah jawaban kuesioner dengan tujuan mengumpulkan informasi yang diberikan kepada wajib pajak orang pribadi sebagai responden yang ada di tempat penelitian. Data yang diinginkan berupa data 
volume 15 Nomor 2, Desember 2019

Halaman $84-92$
Penerapan E-System Perpajakan dan Tingkat Pemahaman Terhadap Kepuasan Wajib Pajak Pribadi di Kota Makassar

penerapan e-sistem perpajakan, tingkat pemahaman dan tingkat kepuasan wajib pajak orang pribadi dikota Makassar.

b. Lokasi Dan Waktu Penelitian

Penelitian ini bertempat di Kota Makassar dan akan dilaksanakan pada Bulan Maret sampai Agustus 2019.

c. Populasi dan Sampel

Populasi pada penelitian ini adalah Wajib PAjak Orang Pribadi yang terdaftar dikota Makassar sebanyak 205.681 orang. Berdasarkan populasinya maka dapat diambil sampel sejumlah 100 orang Wajib pajak yang tersebar di 3 KPP dikota Makassar

d. Tehnik Pengumpulan Data

Teknik pengumpulan data yang digunakan dalam penelitian ini sebagai berikut :

\section{a. Melalui metode survei}

Yaitu dengan menggunakan media angket (kuesioner). Sejumlah pertanyaan akan diajukan kepada responden dan kemudian diminta untuk menjawab pertanyaan tersebut sesuai denganpendapat mereka.

\section{b. Tinjauan Kepustakaan (library reserarch )}

Metode ini dilakukan dengan mempelajari dan menganalisis teori- teori dan konsep-konsep dan dokumen-dokumen yang berhubungan dengan masalah yang sedang diteliti oleh penulis pada buku-buku, makalah dan jurnal guna untuk memperoleh landasan teoritis yang memadai untuk melakukan pembahasan (Widoyoko 2012:49).

\section{c. Mengakses website dan situs-situs}

Metode ini digunakan untuk mencari website ataupun situs-situs yang menyediakan informai sehubungan dengan masalah dalam penelitian dan teori yang mendukung atas penelitian yang dilakukan. 
Volume 15 Nomor 2, Desember 2019

Halaman $84-92$
Penerapan E-system Perpajakan dan Tingkat Pemahaman Terhadap Kepuasan Wajib Pajak Pribadi di Kota Makassar

\section{e. Analisa Data}

Dalam penelitian ini metode analisis yang digunakan adalah analisis regresi llinear berganda. Metode analisis regresi llinear berganda terdiri dari 2 (dua) alat analisis yaitu :

\section{Analisis Statistik Deskriptif}

Statistik Deskriptif merupakan gambaran keadaan suatu data secara umum. Analisis deskriptif memberikan gambaran atau deskripsi suatu data secara numerik yang dilihat dari mean, standar deviasi, varian, maksimum, minimum, sum, range, kurtosis dan skewness (kemencengan distribusi).

\section{Analisis Statistik Infrensial}

Statistik Infrensial merupakan statistik yang digunakan untuk mendeskripsikan data sampel dan hasilnya akan degeneralisasikan (diinferensialkan) untuk populasi dimana sampel diambil. Analisis ini digunakan untuk menjawab masalah dengan sekaligus menguji hipotesis. Analisis inferensial yang digunakan dalam penelitian ini menggunakan alat statistik regresi linear berganda.

\section{HASIL DAN PEMBAHASAN}

\section{a. Hasil Penelitian}

Dalam pelaksanaan penelitian dimana kami membagi kuesioner ke tiga Kantor Pelayanan Pajak (KPP) yakni KPP Makassar Barat, KPP Makassar Selatan, KPP Makassar Utara. Dari 100 Kuesioner yang kami sebar semua terisi dan kembali sesuai harapan. Kuesionner yang kami bagikan kepada wajib pajak terdaftar dimasing masing ketiga kantor pelayanan pajak diMakassar. Dimana tehnik yang kami gunakan adalah mendatangi kantor kantor yang berada dibawah naungan KPP masing masing, Hal Ini kami lakukan karena sudah berkurangnya wajib pajak yang datang melapor kekantor pelayanan pajak masing masing.

Dari hasil pengolahan data yang telah dilakukan oleh peneliti, dapat dijelaskan mengenai variabel-variabel yang terdapat dalam model yang digunakan dalam penelitian ini. Pengolahan 
Volume 15 Nomor 2, Desember 2019

Halaman 84-92
Penerapan E-system Perpajakan dan Tingkat Pemahaman Terhadap Kepuasan Wajib Pajak Pribadi di Kota Makassar

data yang digunakan alat bantu SPSS Vol.22, untuk mempercepat perolehan data hasil yang dapat menjelaskan variabel- variabel yang diteliti. Tabel deskriptif menunjukkan semua variabel yang digunakan dalam model analisis regresi berganda, yaitu variabel Tingkap Kepuasan Wajib Pajak (Y) sebagai variabel dependen, variabel Elektrinik System Perpajakan (X1), dan Tingkat Pemahaman (X2 sebagai variabel independen.

Tabel 1. Statistik Deskriptif Data Penelitian

\section{Descriptive Statistics}

\begin{tabular}{|l|r|r|r|r|r|}
\hline & $\mathrm{N}$ & $\begin{array}{r}\text { Minimu } \\
\mathrm{m}\end{array}$ & Maximum & Mean & $\begin{array}{c}\text { Std. } \\
\text { Deviation }\end{array}$ \\
\hline Y & 100 & 18,00 & 42,00 & 60,00 & 4,08410 \\
X1 & 100 & 9,00 & 36,00 & 45,00 & 3,41269 \\
X2 & 100 & 23,00 & 36,00 & 59,00 & 4,81345 \\
Valid N & 100 & & & & \\
(listwise) & & & & \\
\hline
\end{tabular}

Sumber : Data Primer diolah SPSS V.22

Berdasarkan data pada Output SPSS tersebut menunjukkan jumlah data yang diobservasi (N) sebanyak 100 responden, maka:

1) Untuk kepuasan wajib pajak dari 100 responden, dengan nilai minimum 18,00 , nilai maksimum 42,00, nilai rata-rata (mean) sebesar 60,00 dan standar deviasinya sebesar 4,08. Artinya wajib pajak cukup puas dalam melaksanakan kewajibannya sebagai wajib pajak terkait dengan diberlakukannya $e$-system perpajakan.

2) Untuk penerapan e-system perpajakan pajak dari 100 responden, dengan nilai minimum 9,00, nilai maksimum 36,00, nilai rata-rata (mean) sebesar 45,00 dan standar deviasinya sebesar 3,41. Artinya penerapan e-system perpajakan yang dilakukan cukup baik.

3) Untuk tingkat pemahaman wajib pajak dari 100 respoden, dengan nilai minimum 23,00, nilai maksimum 36,00, nilai rata-rata (mean) sebesar 59,00 dan standar deviasinya sebesar 4,81. Artinya wajib pajak cukup paham tentang tata cara penggunaan $e$-sytem perpajakan. 
Volume 15 Nomor 2, Desember 2019

Halaman 84-92
Penerapan E-system Perpajakan dan Tingkat Pemahaman Terhadap Kepuasan Wajib Pajak Pribadi di Kota Makassar

\section{Hasil Pengujian Asumsi Klasik}

\section{a. Uji Heterokedastisitas}

Pengujian heterokedastisitas dimaksudkan untuk mengetahui kesamaan varian masing-masing variabel Penerapan E-system Perpajakan (X1) dan Tingkat Pengetahuan Perpajakan (X2) terhadap variable Tingkat Kepuasan WP (Y). Pengujian homogenitas terhadap variabel penelitian digunakan uji heterokedastisitas.

Tabel Hasil Uji Heterokedastisitas

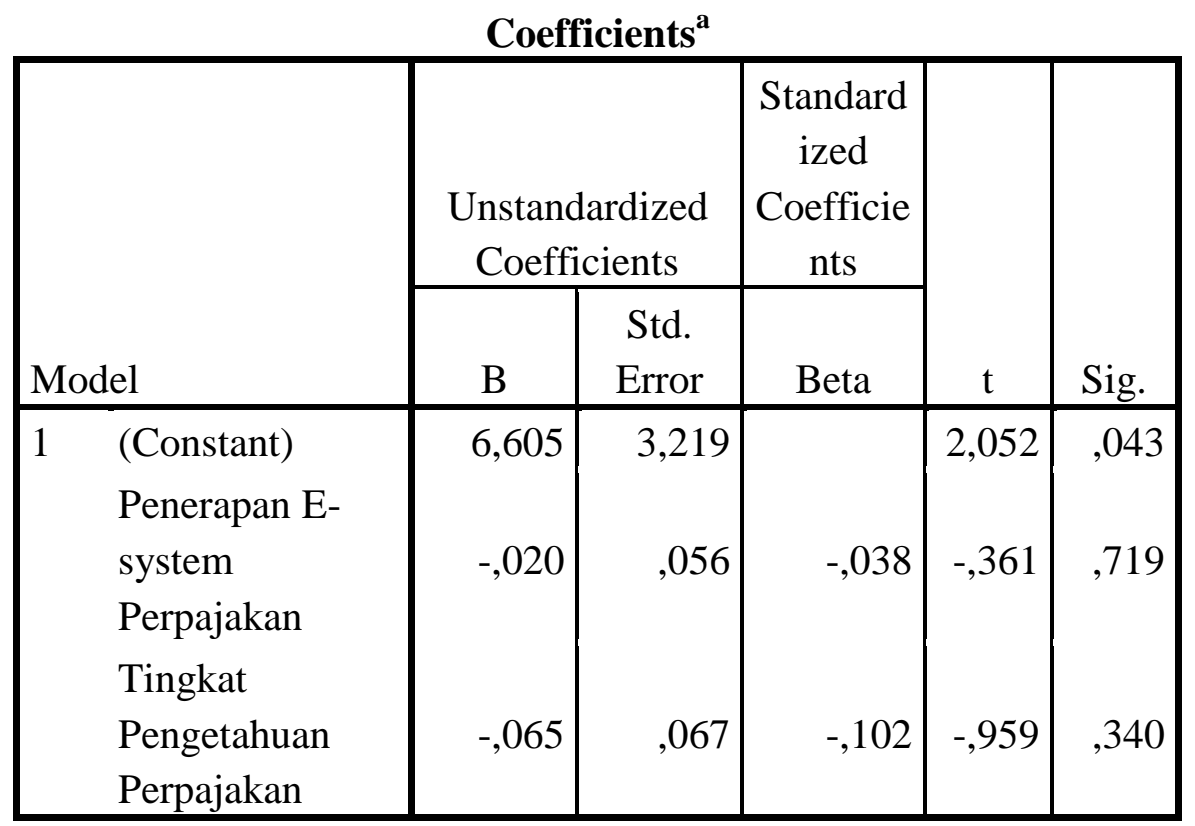


Volume 15 Nomor 2, Desember 2019

Halaman 84-92
Penerapan E-system Perpajakan dan Tingkat Pemahaman Terhadap Kepuasan Wajib Pajak Pribadi di Kota Makassar

Dependent Variable

Berdasarkan Tabel diatas, menunjukkan bahwa nilai signifikan pada pengujian heterokedastisistas untuk variabel Penerapan E-system Perpajakan yaitu $0.719>0.05$, sedangkan pada variabel Tingkat Pemahaman Perpajakan nilai signifikanya $0.340>0.05$, berdasarkan pengujian tersebut dapat disimpulkan bahwa model regresi dalam penelitian ini tidak terjadi heterokedastisitas, disebabkan nilai signifikan untuk variabel Penerapan E-system Perpajakan dan variabel Tingkat Pemahaman Perpajakan nilai signifikanya lebih besar dari 0.05.

\section{b. Hasil Uji Multikolinearitas}

Uji ini bertujuan apakah model regresi ditemukan adanya korelasi diatara variabel bebas. Jika terjadi multikolinearitas sempurna maka penaksir OLS ( Ordinary Least Square ) menjadi tidak tertentu dan varians atau kesalahan standarnya juga menjadi tidak tertentu. Model regresi yang baik seharusnya tidak terjadi korelasi diantara variabel bebas. Jika variabel bebas saling berkorelasi, maka variabel ini tidak ortogonal. Variabel ortogonal adalah variabel bebas yang nilai korelasinya antar sesama variabel bebas lain sama dengan nol. Hasil Uji Multikolinearitas dalam penelitian ini dapat dilihat pada tabel berikut :Tabel Hasil Uji Multikolinearitas

\begin{tabular}{|ll|r|r|}
\hline \multirow{2}{*}{ Model } & \multicolumn{2}{|c|}{ Collinearity Statistics } \\
\cline { 3 - 4 } & Tolerance & VIF \\
\hline 1 & $\begin{array}{l}\text { (Constant) } \\
\text { Penerapan E-sytem } \\
\text { Perpajakan } \\
\begin{array}{l}\text { Tingkat Pemahaman } \\
\text { Perpajakan }\end{array}\end{array}$ &, 906 & 1,104 \\
\hline
\end{tabular}

ent Variable: Tingkat Kepuasan Wajib Pajak 
Volume 15 Nomor 2, Desember 2019

Halaman 84-92
Penerapan E-System Perpajakan dan Tingkat Pemahaman Terhadap Kepuasan Wajib Pajak Pribadi di Kota Makassar

\section{DAFTAR PUSTAKA}

Undang Undang Perpajakan No 16 tahun 2009 tentang Ketentuan Umum Perpajakan

Sugiyono. (2008). Metode Penelitian Analisis Keeratan Hubungan Antar Variabel. Bandung Alfabeta.

Sugiyono. (2017). Statistika Untuk Penelitian.Bandung :Alfabeta.

Resmi, Siti. (2016). Perpajakan :Teori Dan Kasus. Edisi 9. Jakarta :SalembaEmpat.

Sugiharti, MirzaAyu. (2015). Analisa Efektifitas Kelayakan System Pelaporan Pajak Menggunakan E-Filling Terhadap Kepuasan Wajib Pajak. Jurnal Perpajakan. 6 (2) : 1 10 .

Damayanti, Fauzy (2015). Pengaruh Fasilitas Dropbox, E-Spt, Dan E-Filling Dalam Penyampaian Surat Pemberitahuan (SPT) Terhadap Kepuasan Wajib Pajak. Akuntabilitas. 8 (3) : 226-237.

Winerungan Oktaviane Lydia. (2013). Sosialisasi Perpajakan, Pelayanan Fiskus Dan Sanksi Perpajakan Terhadap Keptuhan Wajib Pajak WPOP Di KPP Manado Dan KPP Bitung. Jurnal Emba. 1 (3) : 960-970.

Widjaja, Helen Dan Artus Jaya. (2017). Analisis Penerapan E-System Perpajakan Pada Wajib Pajak Orang PribadiTerhadap Pelaksanaan Self- Assessment System Dalam Memenuhi Kewajiban Perpajakan. Jurnal Ekonomi. 22 (3) : 440-447.

Syahruddin, Herman, Dkk. (2015). Laboratorium Pengolahan Data. 